\title{
Surface Nanocrystallization of 3Cr13 Stainless Steel Induced by High-Current Pulsed Electron Beam Irradiation
}

\author{
Zhiyong Han, ${ }^{1}$ Le Ji, ${ }^{2}$ Jie Cai, ${ }^{2}$ Hui Zou, ${ }^{1}$ Zhiping Wang, ${ }^{1}$ and Qingfeng Guan ${ }^{2}$ \\ ${ }^{1}$ College of Science, Civil Aviation University of China, Tianjin 300300, China \\ ${ }^{2}$ School of Materials Science and Engineering, Jiangsu University, Zhenjiang 212013, China \\ Correspondence should be addressed to Qingfeng Guan; guanqf@ujs.edu.cn
}

Received 7 December 2012; Accepted 1 February 2013

Academic Editor: Kemin Zhang

Copyright (c) 2013 Zhiyong Han et al. This is an open access article distributed under the Creative Commons Attribution License, which permits unrestricted use, distribution, and reproduction in any medium, provided the original work is properly cited.

\begin{abstract}
The nanocrystalline surface was produced on 3Cr13 martensite stainless steel surface using high-current pulsed electron beam (HCPEB) technique. The structures of the nanocrystallized surface were characterized by X-ray diffraction and electron microscopy. Two nanostructures consisting of fine austenite grains $(50-150 \mathrm{~nm})$ and very fine carbides precipitates are formed in melted surface layer after multiple bombardments via dissolution of carbides and crater eruption. It is demonstrated that the dissolution of the carbides and the formation of the supersaturated $\mathrm{Fe}(\mathrm{C})$ solid solution play a determining role on the microstructure evolution. Additionally, the formation of fine austenite structure is closely related to the thermal stresses induced by the HCPEB irradiation. The effects of both high carbon content and high value of stresses increase the stability of the austenite, which leads to the complete suppression of martensitic transformation.
\end{abstract}

\section{Introduction}

Nanomaterials with considerable fine grain sizes and significantly large volume fraction of grain boundaries have exhibited superior mechanical, physical, and chemical properties compared to conventional coarse-grained materials [1]. Surface nanocrystallization of a coarse-grained material provides a new approach to improve the properties of the materials [2]. In practice, surface nanostructures of metal materials can be obtained via severe plastic deformation using surface mechanical attrition treatment (SMAT) [3], highenergy shot peening (HESP) [4], ultrasonic shot peening [5], wire-brushing [6], and so forth.

Recently, the application of energetic beams such as ion, electron, laser, and plasma has been of increasing interest to modify the surface of the metallic materials [7-11]. Among these techniques, the high-current pulsed electron beam (HCPEB) is relatively new $[12,13]$. The energy concentration per pulse is high and could be varied within a relatively large range. Hence, any type of exposure to the heat of the near-surface layers of materials could be achieved: heating, melting, and high-rate evaporation. A subsequent fast cooling is followed by high-rate crystallization of the melt and generation of the thermoelastic dynamic and quasistatic mechanical stresses in the region under irradiation, which inevitably cause high-rate deformation. The combination of the above-mentioned factors due to the HCPEB treatment can promote structural phase transformations and result in the formation of very fine grains within the irradiated surface layers, which would remarkably influence the physicalmechanical properties of the irradiated surface.

In this work, the surface nanocrystallization of $3 \mathrm{Cr} 13$ steel resulted from the HCPEB irradiation is reported. The surface nanocrystallization has potential applications in industries due to its high efficiency, simplicity, and reliability of the HCPEB technique.

\section{Experimental}

The HCPEB equipment, used in this work, is a Nadezhda-2 type, which can produce an electron beam with low electron energy in the range of $10-40 \mathrm{kV}$, high peak current with the range of $10^{2}-10^{3} \mathrm{~A} / \mathrm{cm}^{2}$, short pulsed duration of $0.5-1.5 \mu \mathrm{s}$, and cross-section area $30 \mathrm{~cm}^{2}$. The electron beam is generated by an explosive emission cathode, and the accelerating 
TABLE 1: The compositions of 3Cr13 stainless steel.

\begin{tabular}{lccccccc}
\hline \multirow{2}{*}{ Samples } & \multicolumn{7}{c}{ Chemical composition (wt.\%) } \\
& $\mathrm{C}$ & $\mathrm{Cr}$ & $\mathrm{Mn}$ & $\mathrm{S}$ & $\mathrm{P}$ & $\mathrm{Ni}$ & $\mathrm{Si}$ \\
\hline 3Cr13 & 0.28 & 13.26 & 0.58 & 0.015 & 0.018 & 0.50 & 0.82 \\
\hline
\end{tabular}

voltage, magnetic fields strength, and the anode-collector distance can be adjusted to control the beam energy density. More details about the HCPEB system are described in [7].

A typical 3Crl3 martensite stainless steel was used for study in this work. Its chemical composition was listed in Table 1. Before the electron beam treatment, the samples were machined to dimensions of $14 \mathrm{~mm} \times 10 \mathrm{~mm} \times 5 \mathrm{~mm}$ and austenitized at $1050^{\circ} \mathrm{C}$ for $30 \mathrm{~min}$. Oil quenching terminated this heat treatment. The steel was subsequently tempered at $620^{\circ} \mathrm{C}$ for $2 \mathrm{~h}$. The sample surface was prepared before the HCPEB treatment by mechanical polishing to ensure a similar initial surface state. The energy of the electron beam was kept constant at $24.3 \mathrm{keV}$, and different pulse numbers were used ( 5 and 10 times). For all treatments, the pulsing time was about $1.5 \mu \mathrm{s}$, and $10 \mathrm{~s}$ were set between each pulse.

Surface and cross-section microstructures were characterized using a field emission gun scanning electron microscope (SEM, JEOL JSM-7001F). X-ray diffraction (XRD) was carried out with the $\mathrm{CuK}_{\alpha}$ in a Rigaku D/Max-2500/pc Xray diffractometer. Microstructures were further examined with a transmission electron microscope (TEM) of type JEM2100. The foils used for TEM observations were obtained by preparing one-sided mechanically prethinned, dimpled, and, in the last step, electrolytic thinning of the thin plates until the electron transparency occurred.

\section{Results}

The XRD patterns of the samples before and after the HCPEB irradiations are shown in Figure 1. The evident broadening of the Bragg reflection profiles may be attributed to fine grain size and high value of residual stress. Figure 1 also reveals that the peaks of the martensite phase are shifted to lower angles, signifying the increase of the lattice parameter. It might come from the presence of tensile residual stresses in the surface [12]. Additionally, the peaks of carbide $\left(\mathrm{Cr}_{7} \mathrm{C}_{3}\right)$ vanish completely, and the peaks of $\gamma$ austenite emerge after the irradiations with 5 and 10 pulses. It is indicated that the dissolved $\mathrm{Cr}_{7} \mathrm{C}_{3}$ carbide increased the content of carbon in the martensite, which could also result in the increase of the lattice parameter. Note that the peak intensity of the $\gamma$-Fe phase increases with the number of pulses, indicating that the volume fraction and/or grain sizes of the $\gamma$-phase increases with increasing the number of pulses.

The almost complete dissolving of the carbides is in good agreement with the SEM morphology observations shown in Figure 2. Figure 2(a) reveals the morphology of the treated surface where many craters are present. According to previous studies, such a typical morphology is the result of the local sublayer melting and eruption through the solid outer surface [10, 14]. Figures 2(b) and 2(c) show the typical cross-sectional micrograph of the etched samples after 5 and

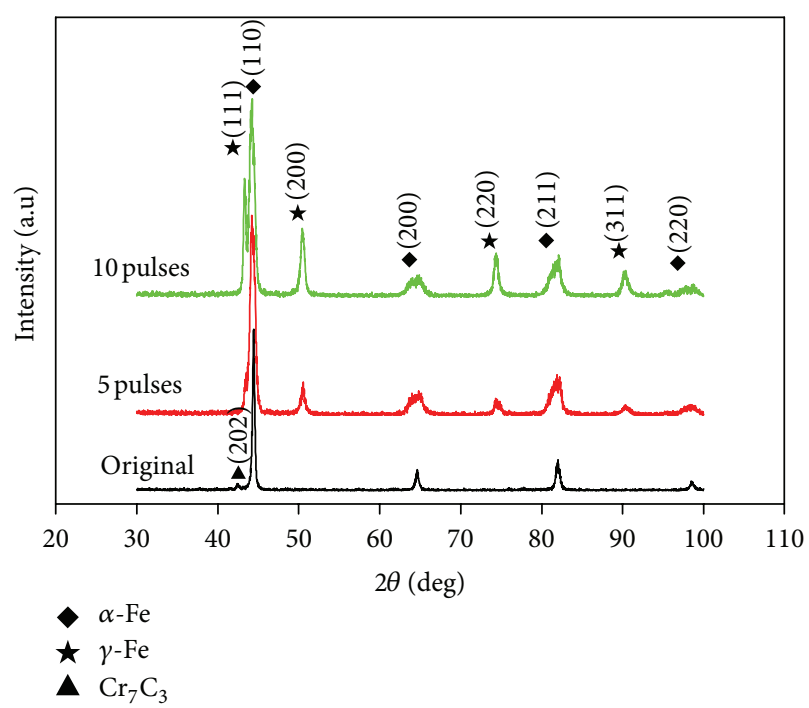

FIGURE 1: XRD patterns of the untreated and treated samples.

10 pulses of the HCPEB irradiation, respectively. The top surface layer, corresponding to the melted layer that is known to be weakly etchable $[9,15]$ as shown in Figures 2(b) and 2(c), appears with a gray contrast, which completely differs from the other part of samples. The depth of the melted layer measured from Figures 2(b) and 2(c) is about $4-6 \mu \mathrm{m}$.

Figure 3(a) exhibits the SEM images of the irradiated surface where the craters are seldom presented. One can see that two typical characteristics of features were formed on the irradiated surface, namely island feature (indicated by letter A) and martensite-like feature (indicated by letter B). High magnification SEM images of both regions, as shown in Figures 3(b) and 3(c), reveal that very fine grains with sizes of $80 \mathrm{~nm}$ are approximately homogeneously dispersed on the irradiated surface, clearly indicating that the melted surface layer is mainly composed of refined grains or subgrains.

TEM micrograph shown in Figure 4(a) shows the typical microstructure of the untreated sample, consisting of $\mathrm{Cr}_{7} \mathrm{C}_{3}$ carbides and martensite. After 5 pulses, as shown in Figure 4(b), the original carbides phase disappears, and the grains with sizes from 50 to $150 \mathrm{~nm}$ are formed. After 10 pulses, similar microstructure was observed in Figure 4(c) compared to its 5 pulses counterpart. The primary differences lie in that a little larger grain sizes (about $80-200 \mathrm{~nm}$ ) were obtained for 10 pulses sample. It is worth noting that the interiors of the fine grain appear to be clean without any detectable defects. The corresponding selected area electron diffraction (SAED) pattern (Figure 4(d)) shows a random crystallographic orientation, indicating the formation of equiaxed fine $\gamma$ austenite grain structure in the melted layer. A careful look at the micrograph in Figures 4(b) and 4(c) also reveals very fine precipitates with sizes below $20 \mathrm{~nm}$. They are often present at the grain boundaries (Figure 4(b)) and triple junctions (Figure $4(\mathrm{c})$ ). Their presence at grain boundary and/or triple junctions suggests that they precipitated from the solid state in nature.

The formation of fine precipitates can be attributed to the rapid quenching process from the supersaturated $\mathrm{Fe}(\mathrm{C})$ solid 


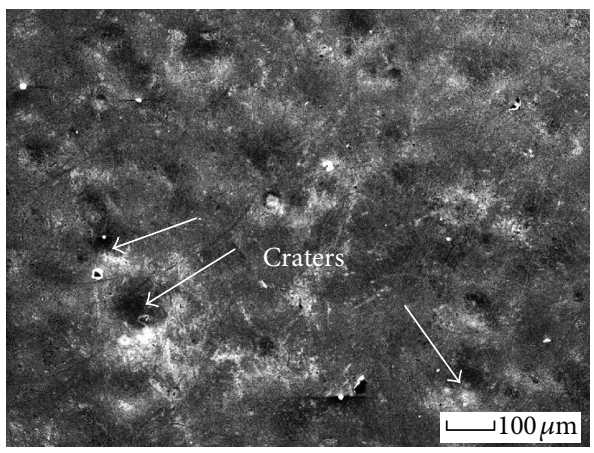

(a)

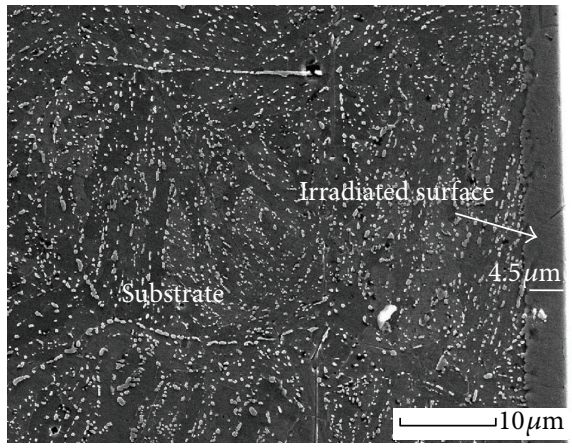

(b)

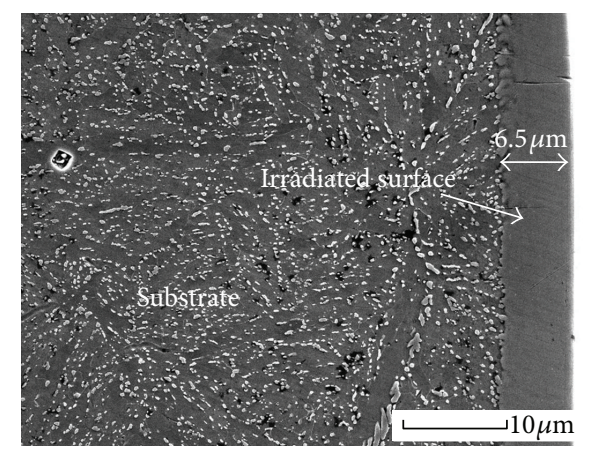

(c)

FIGURE 2: SEM micrographs showing the surface morphology (a), cross-sectional aspect of the samples irradiated for 5 pulses (b), and 10 pulses (c).

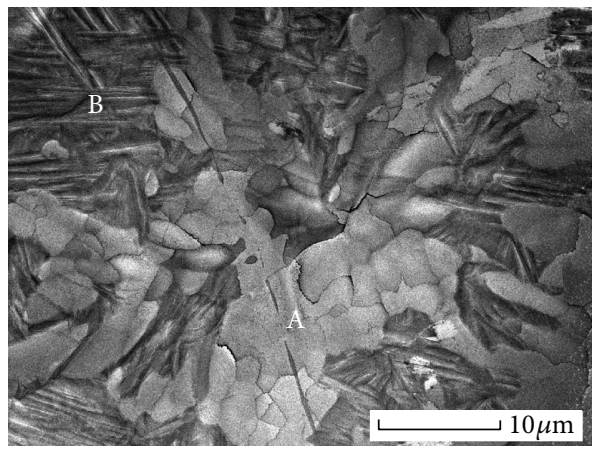

(a)

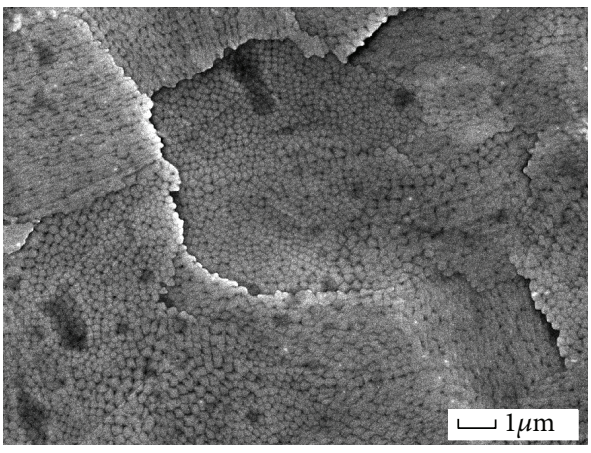

(b)

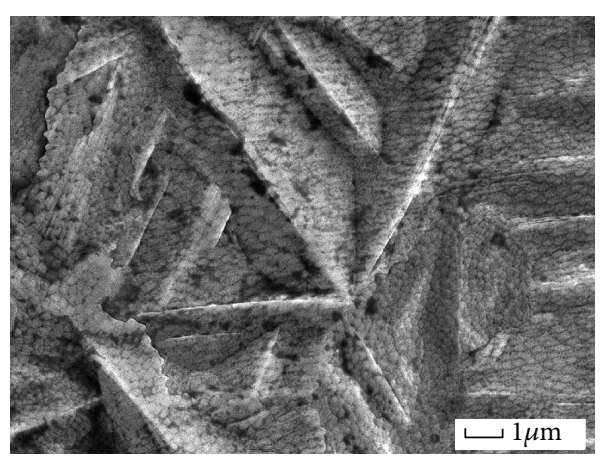

(c)

Figure 3: Typical SEM images of island region (marked A) and martensite-like region (marked B) (a), high-magnification SEM images of the region $\mathrm{A}(\mathrm{b})$, and the region $\mathrm{B}(\mathrm{c})$, showing the surface aspects. 


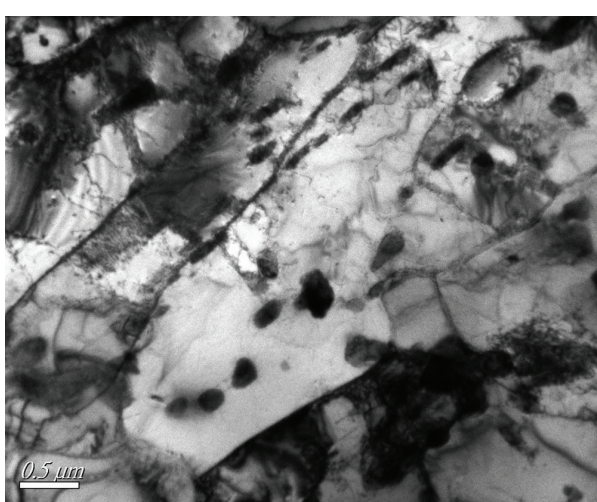

(a)

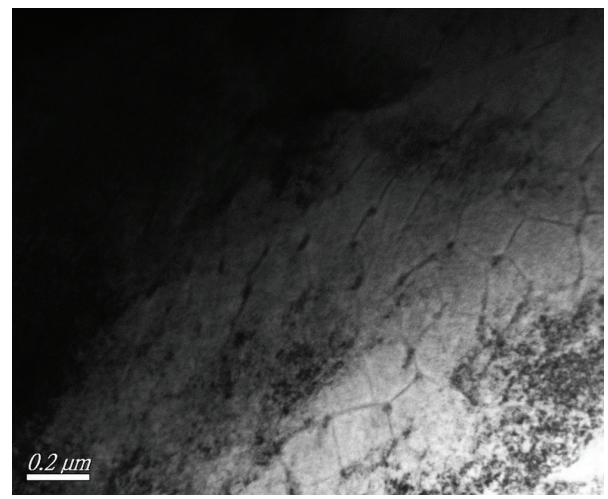

(c)

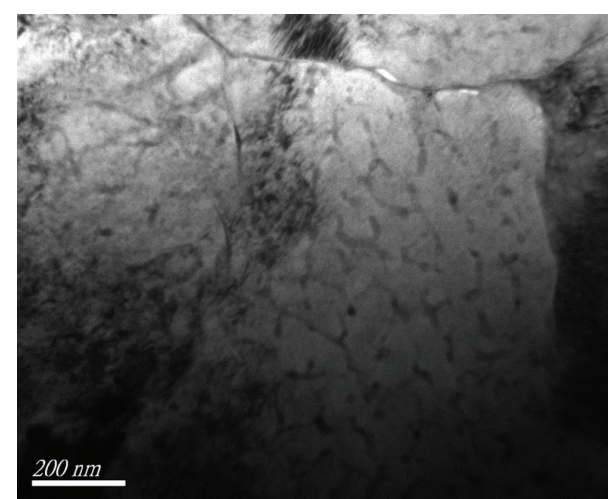

(b)

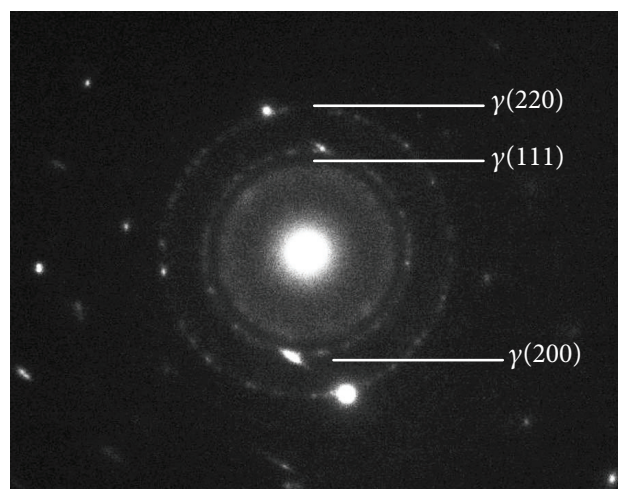

(d)

FIGURE 4: TEM images showing the aspects of the melted surface layer of the 3Cr13 steel, (a) untreated, (b) treated with 5 pulses, (c) treated with 10 pulses, and (d) the corresponding electron diffraction pattern of (c).

solution after the dissolution of the carbides. The transient cooling process inhibits the precipitation and growth of carbides and finally leads to the formation of very fine carbide precipitates.

The surface structure is more pronouncedly characterized by the nanostructure austenite. Stahli et al. observed the formation of a thin layer (about $0.3 \mu \mathrm{m}$ ) of a nanoaustenite structure after irradiating a prequenched bearing steel using a pulsed laser [16]. Similar results were also observed in D2 steel [9, 15] HSS S6-5-2 steel [17], and M50 steel [18] irradiated by the multiple pulses of the HCPEB irradiation. Our observation is a little different from the studies of Zou et al. $[9,15,18]$. In their studies, similar austenite grains were observed after the HCPEB remelting of the D2 steel, and so forth. However, they concluded that the austenite has a high orientation tendency. Comparatively, in our study, a random crystallographic orientation and equiaxed fine austenite grain structure were obtained.

An interesting phenomenon found in the present work is the stabilization of the austenite in the melted layer of the irradiated samples despite the very high cooling rate undergone by the surface of the sample. In the present case, the austenite directly grows from the melt during the rapid solidification process, and the high amounts of $\mathrm{Cr}$ and $\mathrm{C}$ in this phase due to the dissolution of the initial carbide particles are an important factor for suppressing the martensitic transformation [9]. In addition, the very fine size of the austenite grains is another factor for the stabilization of the austenite phase because it will significantly enhance its strength and make the accommodation of a martensitic variant more difficult [15]. Finally, in our opinion, the thermal stress induced by the surface irradiation may be an important factor which should affect the formation of fine austenite. Based on Bardenshtein et al's research [19], austenite is favored by the thermal stresses. When an electron beam irradiates the target, due to the drastic temperature change, a steep temperature gradient is generated along the incident direction of the beam. However, due to the lateral confinement along the surface, the thermal expansion in the directions vertical to the beam is strongly resisted, causing the surface thermal stress. This external force increased the internal stress to an extraordinarily high level [20]. The microstructure of the sublayer beneath the melted layer was also investigated, and the results are shown in Figure 5. It illuminates the substructure in some of the preformed martensite plates, indicating the formation of deformation twins within martensite plates. In Figure 5(b), very high density of dislocations was produced in the interior of preformed martensite plates. Apparently, high density of dislocations was introduced by the intense deformation under the action of high value of applied stresses. It is reasonably believed that the formation of the twins in the preformed martensite plates was mainly resulted from the high applied stresses and the strain rate due to the rapid heating and 


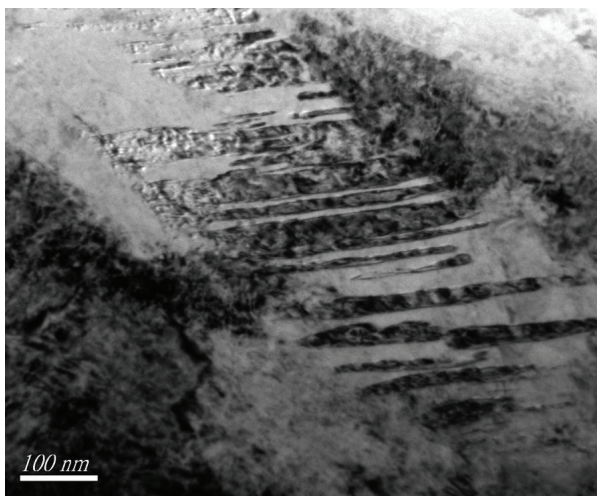

(a)

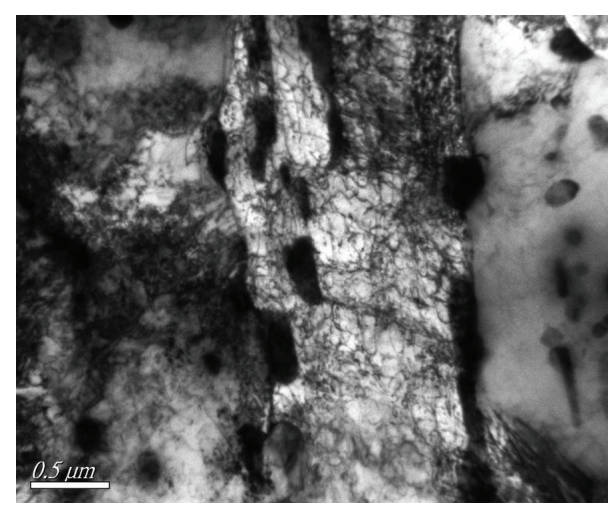

(b)

FIgURE 5: TEM images of deformation twins (a) and dislocation configurations (b), showing the deformation microstructures in the preformed martensite beneath melted surface layer.

cooling caused by HCPEB irradiation [20]. Therefore, the formation of fine austenite structure in this work is closely related to the thermal stresses induced by HCPEB irradiation.

It is well known that surface nanostructures exhibit superior mechanical properties compared to conventional coarsegrained materials. Moreover, high value of residual stresses accumulated in the subsurface layer below the top nanostructure surface are favored to the improvement of the surface performance. In conclusion, HCPEB irradiations provide an effective method for fabricating surface nanostructure.

\section{Conclusions}

The initial samples of 3Cr13 steel were irradiated by highcurrent pulsed electron beam. The surface structures were investigated in detail using X-ray diffraction, SEM, and TEM. According to experimental results, we conclude as follows.

After HCPEB posttreatments, irradiated surface melted, and a supersaturated $\mathrm{Fe}(\mathrm{C})$ solid solution phase was formed after multiple bombardments. Rapid solidification caused the formation of two nanostructures consisting of fine austenite grains $(50-150 \mathrm{~nm})$ and very fine carbides precipitates in the melted surface layer via dissolution of carbides and crater eruption. Rapid heating and cooling induced heavy plastic deformation beneath the melted layer, which lead to the formation of deformation twins and high density of dislocations within martensite plates. The dissolution of the carbides and the formation of the supersaturated $\mathrm{Fe}(\mathrm{C})$ solid solution play a determining role on the microstructure evolution. Furthermore, the formation of the fine austenite structure is closely related to the thermal stresses induced by the HCPEB irradiation. The effects of both high carbon content and high value of stresses increase the stability of the austenite, which leads to the complete suppressing of martensitic transformation.

\section{Acknowledgments}

This work was supported by the National Natural Science Foundation of China (U1233111 and 50671042), to which the authors are very grateful.

\section{References}

[1] R. W. Cahn, "Nanostructured materials," Nature, vol. 348, no. 6300, pp. 389-390, 1990.

[2] Z. B. Wang, N. R. Tao, W. P. Tong, J. Lu, and K. Lu, "Diffusion of chromium in nanocrystalline iron produced by means of surface mechanical attrition treatment," Acta Materialia, vol. 51, no. 14, pp. 4319-4329, 2003.

[3] Z. B. Wang, N. R. Tao, S. Li et al., "Effect of surface nanocrystallization on friction and wear properties in low carbon steel," Materials Science and Engineering A, vol. 352, no. 1-2, pp. 144149, 2003.

[4] C. H. Chen, R. M. Ren, X. J. Zhao, and Y. J. Zhang, "Surface nanostructures in commercial pure Ti induced by high energy shot peening," Transactions of Nonferrous Metals Society of China, vol. 14, no. 2, pp. 215-218, 2004.

[5] X. Wu, N. Tao, Y. Hong, B. Xu, J. Lu, and K. Lu, "Microstructure and evolution of mechanically-induced ultrafine grain in surface layer of AL-alloy subjected to USSP," Acta Materialia, vol. 50, no. 8, pp. 2075-2084, 2002.

[6] M. Sato, N. Tsuji, Y. Minamino, and Y. Koizumi, "Formation of nanocrystalline surface layers in various metallic materials by near surface severe plastic deformation," Science and Technology of Advanced Materials, vol. 5, no. 1-2, pp. 145-152, 2004.

[7] A. D. Pogrebnjak, V. S. Ladysev, N. A. Pogrebnjak et al., "Comparison of radiation damage and mechanical and tribological properties of $\alpha$-Fe exposed to intense pulsed electron and ion beams," Vacuum, vol. 58, no. 1, pp. 45-52, 2000.

[8] L. E. Xiaoyun, Y. Sha, Z. Weijiang, H. Baoxi, W. Yugang, and X. Jianming, "Computer simulation of thermal-mechanical effects of high intensity pulsed ion beams on a metal surface," Surface and Coatings Technology, vol. 128-129, no. 1, pp. 381-386, 2000.

[9] J. X. Zou, T. Grosdidier, K. M. Zhang, and C. Dong, "Mechanisms of nanostructure and metastable phase formations in the surface melted layers of a HCPEB-treated D2 steel," Acta Materialia, vol. 54, no. 20, pp. 5409-5419, 2006.

[10] K. M. Zhang, J. X. Zou, T. Grosdidier, and C. Dong, "Craterformation-induced metastable structure in an AISI D2 steel treated with a pulsed electron beam," Vacuum, vol. 86, no. 9, pp. 1273-1277, 2012.

[11] J. X. Zou, K. M. Zhang, S. Z. Hao, C. Dong, and T. Grosdidier, "Mechanisms of hardening, wear and corrosion improvement of 316 L stainless steel by low energy high current pulsed 
electron beam surface treatment," Thin Solid Films, vol. 519, no. 4, pp. 1404-1415, 2010.

[12] K. M. Zhang, J. X. Zou, B. Bolle, and T. Grosdidier, "Evolution of residual stress states in surface layers of an AISI D2 steel treated by low energy high current pulsed electron beam," Vaccum, vol. 87, pp. 60-68, 2013.

[13] K. M. Zhang, J. X. Zou, T. Grosdidier, and C. Dong, "Microstructure and property modifications of an AISI H13 (4Cr5MoSiV) steel induced by pulsed electron beam treatment," Journal of Vacuum Science and Technology A, vol. 28, no. 6, pp. 1349-1355, 2010.

[14] Y. Qin, X. G. Wang, C. Dong et al., “Temperature field and formation of crater on the surface induced by high current pulsed electron beam bombardment," Acta Physica Sinica, vol. 52, no. 12, pp. 3043-3048, 2003.

[15] J. X. Zou, T. Grosdidier, K. M. Zhang, B. Gao, S. Z. Hao, and C. Dong, "Microstructures and phase formations in the surface layer of an AISI D2 steel treated with pulsed electron beam," Journal of Alloys and Compounds, vol. 434-435, pp. 707-709, 2007.

[16] G. Stähli and C. Sturzenegger, "On the formation of austentic boundary layers by short laser-pulse reaction with steel," Scripta Metallurgica, vol. 12, no. 7, pp. 617-622, 1978.

[17] V. P. Rotshtein, D. I. Proskurovsky, G. E. Ozur, Y. U. F. Ivanov, and A. B. Markov, "Surface modification and alloying of metallic materials with low-energy high-current electron beams," Surface and Coatings Technology, vol. 180-181, pp. 377381, 2004.

[18] G. Z. Tang, F. J. Xu, G. H. Fan, X. X. Ma, and L. Q. Wang, "Mechanisms of microstructure formations in M50 steel melted layer by high current pulsed electron beam," Nuclear Instruments and Methods in Physics Research B, vol. 288, pp. 1-5, 2012.

[19] A. Bardenshtein, L. Bushnev, E. Dudarev, A. Markov, and V. Rotshtein, "Thermal stresses and twinning in thin copper samples irradiated with a high-current electron beam," in Proceedings of the 1st International Congress on Radiation Physics, High Current Electronics and Modification of Materials, vol. 3, pp. 43-52, Tomsk, Russia, 2000.

[20] Q. F. Guan, Q. Y. Zhang, C. Dong, and G. T. Zou, "Deformation twining in single-crystal aluminum induced by high-current pulsed electron beam," Journal of Materials Science, vol. 40, no. 18, pp. 5049-5052, 2005. 

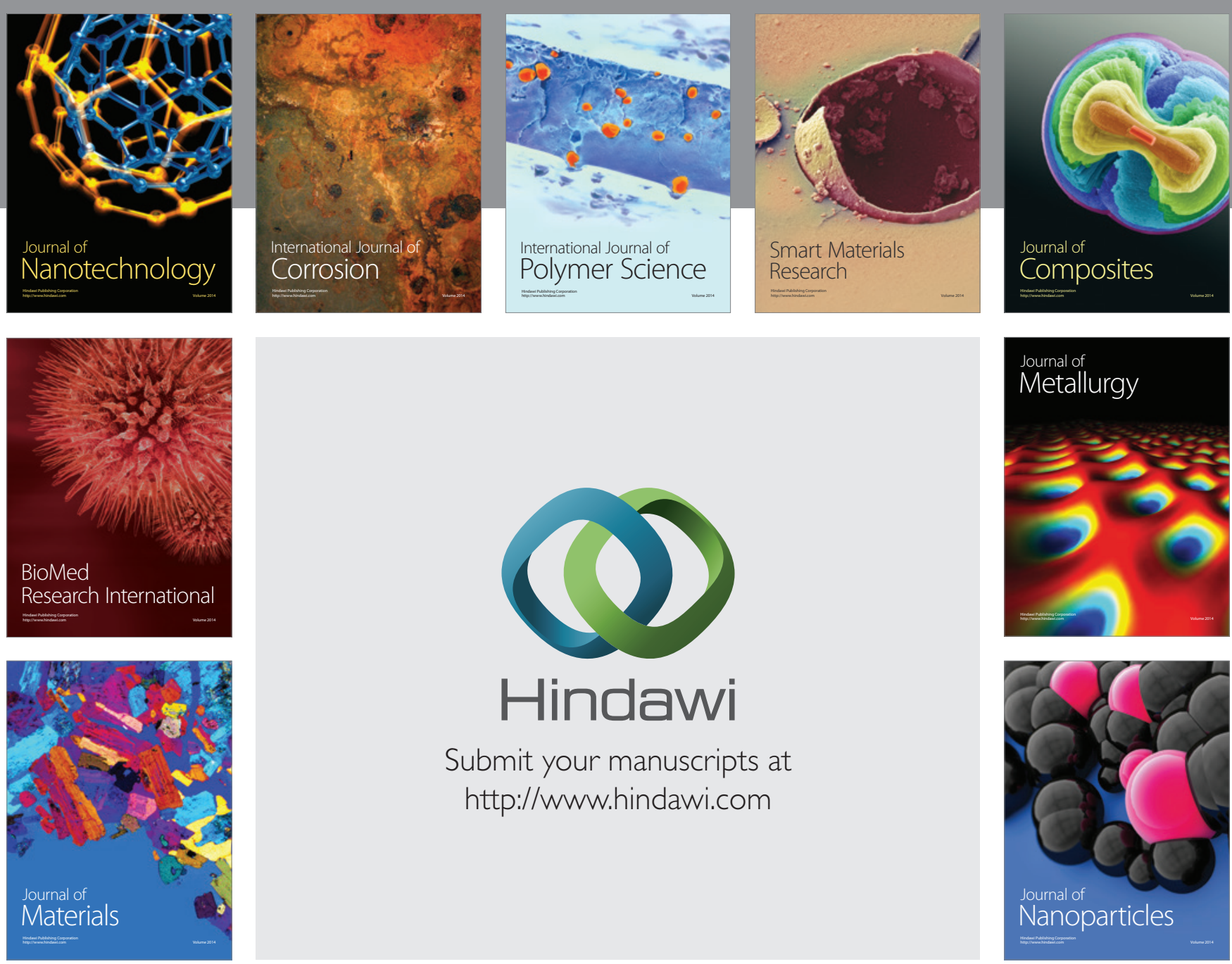

Submit your manuscripts at http://www.hindawi.com
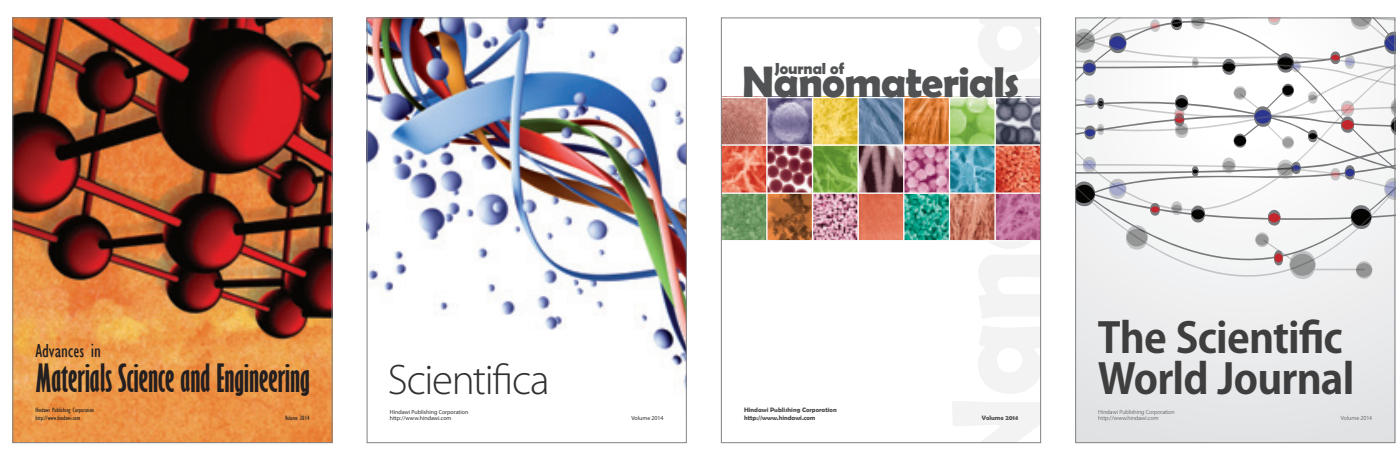

\section{The Scientific World Journal}
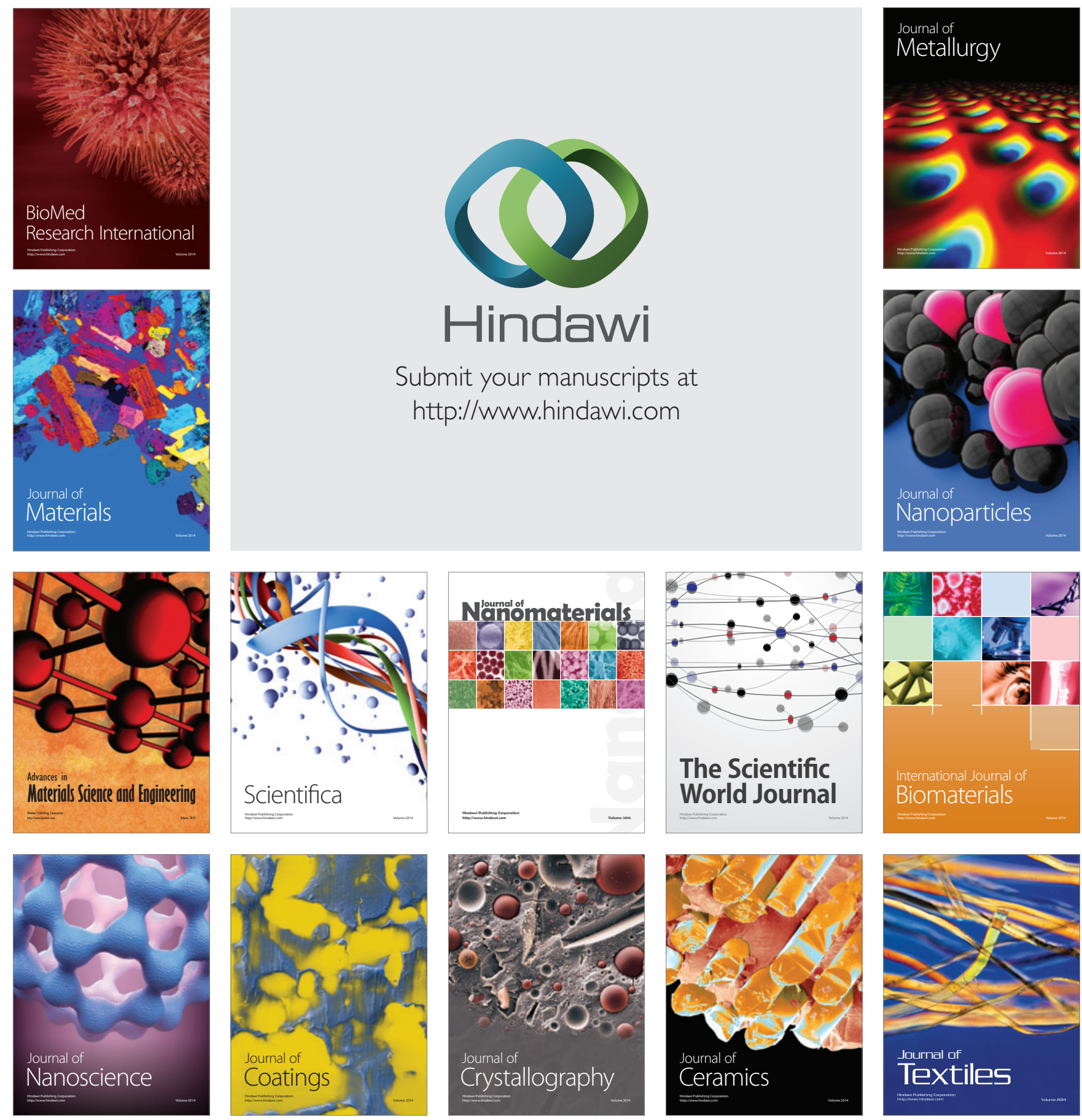